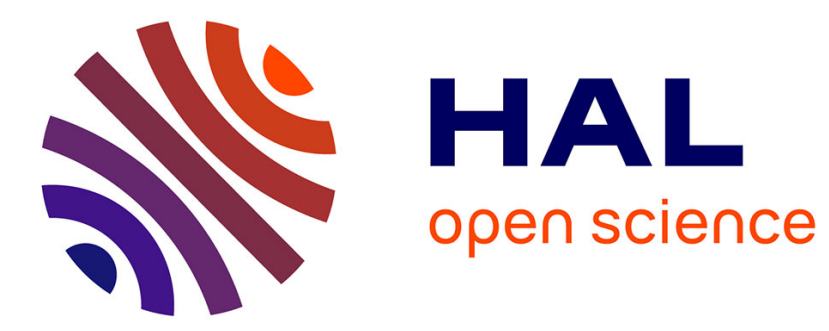

\title{
4d Auger transitions from excited states in Sm metal
}

G. Dufour, R.C. Karnatak, J.-M. Mariot, C. Bonnelle

\section{To cite this version:}

G. Dufour, R.C. Karnatak, J.-M. Mariot, C. Bonnelle. 4d Auger transitions from excited states in Sm metal. Journal de Physique Lettres, 1976, 37 (5), pp.119-121. 10.1051/jphyslet:01976003705011900 . jpa-00231252

\section{HAL Id: jpa-00231252 https://hal.science/jpa-00231252}

Submitted on 1 Jan 1976

HAL is a multi-disciplinary open access archive for the deposit and dissemination of scientific research documents, whether they are published or not. The documents may come from teaching and research institutions in France or abroad, or from public or private research centers.
L'archive ouverte pluridisciplinaire HAL, est destinée au dépôt et à la diffusion de documents scientifiques de niveau recherche, publiés ou non, émanant des établissements d'enseignement et de recherche français ou étrangers, des laboratoires publics ou privés. 


\title{
4d AUGER TRANSITIONS FROM EXCITED STATES IN Sm METAL (*)
}

\author{
G. DUFOUR, R. C. KARNATAK, J.-M. MARIOT and C. BONNELLE \\ Laboratoire de Chimie Physique « Matière et Rayonnement » $(* *)$ \\ Université Pierre-et-Marie-Curie, 11, rue P.-et-M.-Curie, 75231 Paris Cedex 05, France
}

(Reçu le 20 février 1976, accepté le 15 mars 1976)

\begin{abstract}
Résumé. - Le spectre Auger $\mathrm{N}_{4,5}$ de $\operatorname{Sm}\left(4 \mathrm{~d}^{10} 4 \mathrm{f}^{5}\right)$ excité soit par la raie $\mathrm{AlK} \alpha$, soit par des électrons de 4,8 keV, a été analysé. L'influence de ces deux modes d'excitation est discutée. La présence d'un pic supplémentaire dans le spectre obtenu par bombardement électronique est attribuée à un processus d'autoionisation ayant pour état initial l'atome excité $4 d^{9} 4 f^{5+1}$.

Abstract. - The $\mathrm{N}_{4,5}$ Auger spectrum of $\mathrm{Sm}\left(4 \mathrm{~d}^{10} 4 \mathrm{f}^{5}\right)$ excited by $\mathrm{AlK} \alpha$ radiation or by $4.8 \mathrm{keV}$ electrons has been analysed. The influence of these excitation modes is discussed. The presence of an additional peak in the electron induced spectrum is explained by invoking an autoionization transition in which the initial state is the $4 d^{9} 4 f^{5+1}$ excited atom.
\end{abstract}

1. Introduction. - Recent studies of the $3 \mathrm{~d}$ and 4d X-ray emission and absorption spectra have provided much information on the ionization and excitation processes in rare earth solids. The $n d$ $(n=3,4)$ absorption spectra are well interpreted by $n \mathrm{~d}^{10} 4 \mathrm{f}^{m} \rightarrow n \mathrm{~d}^{9} 4 \mathrm{f}^{m+1}$ excitation transitions [1-3]. Two types of transitions are observed in the emission spectra depending on whether the initial state is the $n \mathrm{~d}^{9} 4 \mathrm{f}^{m}$ ion or the $n \mathrm{~d}^{9} 4 \mathrm{f}^{m+1}$ excited atom : the former are the normal X-ray lines [4, 5], the latter - which are the inverse of the absorption lines - are called resonance lines [4]. This led to the suggestion that the nonradiative counterpart of both transitions must be present in the 4d Auger spectra of rare earth solids [6]. The nonradiative transitions occuring from a $4 d^{9} 4 f^{m}$ ion are normal Auger transitions (NAT), but those from a $4 d^{9} 4 f^{m+1}$ excited atom are autoionizing transitions (AT).

It is possible to confirm this interpretation by using two different modes of $4 \mathrm{~d}$ hole creation : X-ray irradiation or electron bombardment, because they give different amounts of excited and ionized initial states. This will be discussed in section 2 . The experimental set-up is briefly described in section 3 . The $4 d$ Auger spectra of $\operatorname{Sm}\left(4 d^{10} 4 f^{5}\right)$ is presented and discussed in section 4 .

2. d hole creation in rare earth atoms. - Let us now discuss how the ratio $r=$ (excited atoms/ionized

(*) Part of "Thèse de Doctorat d'Etat " to be presented by G. Dufour to Université P.-et-M.-Curie (1976).

(**) Laboratoire associé au C.N.R.S. atoms) depends on the mode of $\mathrm{d}$ hole creation. An excited atom can be created either by bombarding the samples with electrons having an energy equal to or larger than that of the absorption line, or by photons which must have the exact energy of this line. In the case of irradiation by X-rays emitted by $\mathrm{Al}$ or $\mathrm{Mg}$ targets, a $\mathrm{K} \alpha$ photon can lose its full energy if it ionizes an atom in the $n$ d shell, but only the bremstrahlung photons having the exact energy of the absorption line can be used to excite it. The $\mathrm{K} \alpha$ emission being much more intense than the bremstrahlung, the ratio $r$ will then be rather small. On the contrary in the case of electron bombardment, the impinging electron can lose part of its energy either to excite or to ionize the $n$ d electron, yielding both excited atoms and ions.

Thus by changing from photon irradiation to electron bombardment, the ratio $r$ is increased and so must the ratio $\mathrm{AT} / \mathrm{NAT}$.

3. Experimental. - The Sm Auger spectra were induced either by the $\mathrm{X}$-rays emitted from an $\mathrm{Al}$ anode or by $4.8 \mathrm{keV}$ electrons and analysed in an AEIES 200B electron spectrometer equipped with ion pumps giving ultra-high vacuum working conditions. A multichannel analyser fitted to the spectrometer is used to accumulate data from many scans, so as to extract the low level Auger signal from the background. The whole instrument will described elsewhere [7].

The samples are in situ evaporated films. They are regenerated before the 0 (1s) photoelectron signal grows to $2 \%$ of the $\operatorname{Sm}\left(3 d_{5 / 2}\right)$ peak. 
The resolution of the analyser is set to give a FWHM of $1.5 \mathrm{eV}$ on the $\mathrm{Au}\left(4 \mathrm{f}_{7 / 2}\right)$ peak. The energy scale is calibrated to give that peak at $83.8 \mathrm{eV}$ binding energy [8]. Due to poor peak intensity compared to the large background, the accuracy of Auger peak location is estimated to be only $\pm 0.4 \mathrm{eV}$.

4. Results and discussion. - The electron induced $4 \mathrm{~d}$ Auger spectrum of $\mathrm{Sm}$ is given in figure $1 a$. It is difficult to compare it with a previously reported spectrum given in the derivative form [9], but the positions of the main features are in good agreement. Figure $1 b$ shows the photon induced spectrum. The peaks common to both spectra are due to NAT but an interpretation is complicated by the many splittings - not all of which are clearly understood yet [10] - of the X-ray photoelectron spectra of Sm core levels. The 102 and $122 \mathrm{eV}$ peaks could be tentatively attributed to $4 d-5 p 4 f$ and $4 d-4 f$ f NAT respectively [7].
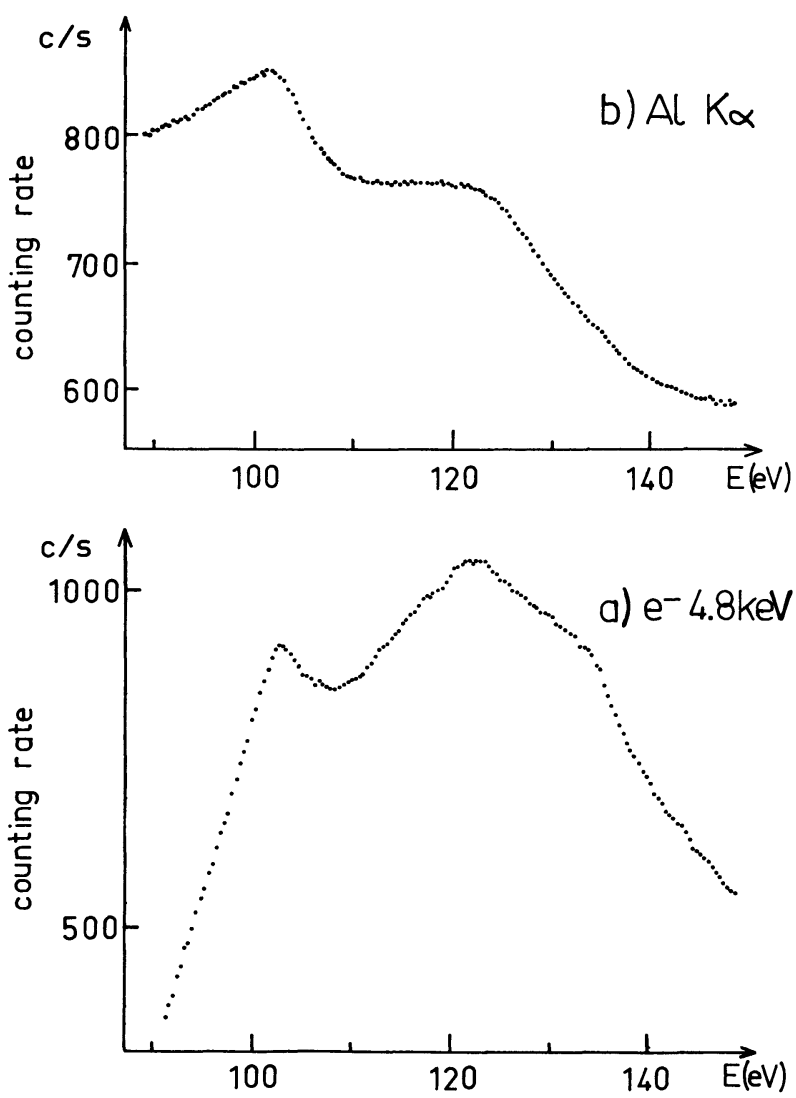

Fig. 1. - 4d Auger spectrum of Sm metal. a) Electron (4.8 keV) induced spectrum (320 scans; $0.2 \mathrm{~s} /$ channel). b) Photon ( $\mathrm{AlK} \alpha$ ) induced spectrum (160 scans; $0.2 \mathrm{~s} /$ channel). The electron induced spectrum has required twice the number of scans than the photon induced one due to instabilities in the electron gun current.

From the figure, it can be seen that the electron induced spectrum, when compared to the photon induced one, presents an additional feature at $\sim 133 \mathrm{eV}$. The Gd and Dy 4d Auger spectra show also such an extra peak [7]. This peak is attributed to an AT, i.e. to electrons expelled from a $4 d^{9} 4 f^{5+1}$ excited $\mathrm{Sm}$ atom.

A confirmation of this interpretation can be obtained by calculating the threshold energy beyond which no 4d NAT can occur. The threshold energy of a 4d-XY NAT can be evaluated from :

$$
E(4 \mathrm{~d}-\mathrm{XY})=E(4 \mathrm{~d})-E(\mathrm{X})-E(\mathrm{Y})
$$

where the energies $E(4 \mathrm{~d}), E(\mathrm{X})$ and $E(\mathrm{Y})$ are obtained from X-ray photoelectron spectroscopy (XPS) measurements. Choosing for $E(4 \mathrm{~d})$ the maximum binding energy $(E(4 \mathrm{~d})=135.0 \mathrm{eV})$ and for $E(\mathrm{X})$ and $E(\mathrm{Y})$ the minimum binding energy of the loosest bound electrons $(E(4 \mathrm{f})=5.0 \mathrm{eV})$, a value of $125 \mathrm{eV}$ is obtained, which is lower than the energy of the extra peak ( $133 \mathrm{eV})$.

The nonradiative counterpart of a resonance emission line is the ejection of an electron in the $\mathrm{X}$ shell with a kinetic energy $E$ given by :

$$
E=E_{\mathrm{R}}-E(\mathrm{X})
$$

where $E_{\mathrm{R}}$ is the energy of the resonance line. $E_{\mathrm{R}}$ can be reached from either soft X-ray [11, 12] or electron inelastic scattering [13] measurements. Both are in agreement and we have chosen for $E_{\mathrm{R}}$ the energy corresponding to the $4 d^{10} 4 f^{5} \rightarrow 4 d^{9} 4 f^{5+1}$ excitation transition of highest probability, i.e. $140 \mathrm{eV}$. Using for $E(X)$ the energies of the 4f XPS peaks [10], AT are expected at 131, 132.8 and $135 \mathrm{eV}$. So the extra peak located at $133.6 \mathrm{eV}$ can be attributed to a

$$
(4 \mathrm{~d} \rightarrow 4 \mathrm{f})-4 \mathrm{f} \mathrm{AT},
$$

i.e. to an autoionization process consecutive to the excitation of a $4 \mathrm{~d}$ electron into the $4 \mathrm{f}$ states.

We note that the $(4 d \rightarrow 4 f)-5 p$ AT should be expected at $\sim 118 \mathrm{eV}$ [7], and could explain the intensity enhancement observed for the $122 \mathrm{eV}$ peak when going from the photon to the electron induced spectrum.

5. Conclusion. - We have compared the $4 \mathrm{~d}$ Auger spectra of $\mathrm{Sm}$ metal induced by photons and by electrons. The differences observed between these two types of spectra can be understood by invoking autoionization transitions in which an electron is ejected from a $4 d^{9} 4 f^{5+1}$ excited atom. Such a type of transition must also be present in the $3 \mathrm{~d}$ Auger spectrum of $\mathrm{Sm}$, and more generally in the $\mathrm{d}$ Auger spectra of rare earths.

Acknowledgments. - The authors wish to thank the Groupement Régional de Mesures Physiques pour la Chimie, Paris Centre (Centre de Spectrochimie) for its financial support. 


\section{References}

[1] Sugar, J., Phys. Rev. B 6 (1972) 1764.

[2] Bonnelle, C., Karnatak, R. C. and Sugar, J., Phys. Rev. $A 9$ (1974) 1920.

[3] Sugar, J., Phys. Rev. B 5 (1972) 1785.

[4] Bonnelle, C. and Karnatak, R. C., J. Physique Colloq. 32 (1971) C4-230.

[5] La Villa, R. E., Phys. Rev. A 9 (1974) 1801.

[6] Dufour, G. and Bonnelli. C., J. Physique Lett. 35 (1974) L-255.

[7] Dufour, G., Thèse de Doctorat d'Etat, Université P.-et-M.Curie, Paris (1976).

[8] Johannson, G., Hedman, J., Berndtsson, A., Klasson, M. and NiLsson, R., J. Electron Spectrosc. 2 (1973) 295.
[9] Färber, W. and BraUN, P., Surf. Sci. 41 (1974) 195.

[10] Dufour, G., Karnatak, R. C., Mariot, J.-M. and Bonnelle, C., to be published.

[11] Haensel, R., Rabe, P. and Sonntag, B., Solid State Commun. 8 (1970) 1845.

[12] Fomichev, V. A., GribovskiI, S. A. and Zimkina, T. M., Proceedings of the International Symposium X-Ray Spectra and Electronic Structure of Matter (Ed. A. Faessler and G. Wiech), München (1972), Vol. II, p. 191.

[13] Trebbia, P. and Colliex, C., Phys. Status Solidi (b) 58 (1973) 523. 